\title{
SMR
}

\section{Genetic variability of $E R C C 1$ and $E R C C 2$ genes involved in the nucleotide excision repair pathway influences the treatment outcome of gastric cancer}

\author{
D.L. Zheng',2, G.D. Tang ${ }^{1}$, Y.N. Chen ${ }^{2}$, T. Zhang ${ }^{2}$ and M.B. Qin ${ }^{1}$ \\ ${ }^{1}$ Department of Gastroenterology, \\ The First Affiliated Hospital of Guangxi Medical University, Nanning, China \\ ${ }^{2}$ Department of Gastroenterology, \\ Ruikang Hospital Affiliated to Guangxi University of Chinese Medicine, \\ Nanning, China \\ Corresponding author: G.D. Tang \\ E-mail: tanggudd@163.com \\ Genet. Mol. Res. 15 (2): gmr. 15027384 \\ Received August 6, 2015 \\ Accepted December 9, 2015 \\ Published April 26, 2016 \\ DOI http://dx.doi.org/10.4238/gmr.15027384
}

\begin{abstract}
We conducted a prospective study to investigate whether ERCC1 rs11615 and rs3212986 and ERCC2 rs13181 and rs1799793 gene polymorphisms could serve as potential biomarkers for the prognosis of gastric cancer. Between January 2010 and December 2012, 246 patients with pathologically proven gastric cancer who were receiving platinum-based chemotherapy were recruited from the First Affiliated Hospital of Guangxi Medical University. The genotyping of the gene polymorphisms was conducted using the polymerase chain reaction coupled with restriction fragment length polymorphism. By logistic regression analysis, we found that the AA genotype of ERCC1 rs3212986 was associated with lower rates of complete remission and partial remission following chemotherapy in gastric cancer patients, and the OR $(95 \% \mathrm{CI})$ was $0.19(0.06-0.60)$. We found that the AA genotype of
\end{abstract}


rs3212986 was correlated with higher risk of death from gastric cancer according to the Cox proportional hazards model, and the adjusted HR $(95 \% \mathrm{CI})$ was 1.60 (0.81-3.16). However, we found no association between ERCC1 rs11615, ERCC2 rs13181, and ERCC2 rs1799793 and overall survival of gastric cancer. In conclusion, the results of the present retrospective study indicate that the ERCC1 rs3212986 gene polymorphism has a significant effect on the pharmacokinetics and treatment outcome of gastric cancer.

Key words: $E R C C 1$; $E R C C 2$; Polymorphism; Gastric cancer; Treatment outcome

\section{INTRODUCTION}

Gastric cancer is one of the most common malignancies in the world, and its morbidity and mortality rates rank second out of all tumors (Parkin et al., 2005). Gastric cancer can be cured if tumors are discovered early and removed surgically. However, most patients are diagnosed at an advanced stage. The development of valid therapies for advanced gastric cancer is slow (Ohtsu, 2008). Currently, systemic chemotherapy is the primary means for treatment of advanced gastric cancer, but generated resistance is a major cause of chemotherapy failure. The initiation and progression of gastric cancer is a complex process that involves both genetic and environmental factors (Ludwig and Weinstein, 2005; Yang et al., 2012). Therefore, identification of genetic biomarkers that can predict the prognosis for gastric cancer patients would greatly improve individualized therapy, post-operational treatment, and follow-up strategies.

DNA repair systems, including nucleotide excision repair (NER), base excision repair, mismatch repair, and double-strand break repair, play a critical role in maintaining the stability and integrity of the genome (Lindahl and Wood, 1999; Goode et al., 2002). NER is a versatile system that monitors and repairs DNA damage, and it is induced by endogenous and exogenous factors, including therapeutic agents (de Laat et al., 1999). Therefore, alteration of NER capacity may influence the individualized clinical outcome for patients with gastric cancer. The excision repair cross-complementation group 1 (ERCC1) enzyme is an essential factor involved in DNA damage repair, and ERCC2 is responsible for the damage unwinding process (Matsunaga et al., 1995; Evans et al., 1997; Enzlin and Schärer, 2002; Coin et al., 2007). We conducted a prospective study to determine whether ERCC1 rs11615 and rs3212986, and ERCC2 rs13181 and rs1799793 gene polymorphisms could serve as potential biomarkers for prognosis in gastric cancer.

\section{MATERIAL AND METHODS}

\section{Study population}

Our study consisted of 246 patients with pathologically proven gastric cancer who were receiving platinum-based chemotherapy were recruited from the First Affiliated Hospital of Guangxi Medical University between January 2010 and December 2012. The exclusion criteria of this study are patients who had a history of other malignant tumor except for gastric cancer, had received preoperative radiotherapy or chemotherapy. Ultimately, 224 patients with 
gastric cancer were included in our study, and the participation rate was $91.06 \%$.

The gastric cancer patients and control subjects were investigated by trained nurses who collected data on demographic and clinical characteristics, such as gender, age, histological classification, TNM stage, and lymphatic metastasis. All the gastric cancer patients were histopathologically confirmed and classified based on Lauren's classification. All study subjects signed written informed consent prior to participating in this study. The protocol of this study was approved by the Ethics Committee of the First Affiliated Hospital of Guangxi Medical University. Our study was carried out according to the Declaration of Helsinki.

All gastric cancer patients underwent platinum-based chemotherapy after participating into this study. The treatment response to platinum-based chemotherapy was assessed using the World Health Organization criteria (Miller et al., 1981). The responsive to chemotherapy included complete remission (CR) and partial remission (PR), and the non-responsive to chemotherapy included stable disease and progressive disease. Overall survival (OS) was taken as the endpoint indicator. The followed-up period was between January 2010 and December 2014.

\section{Genotyping}

A peripheral blood sample $(5 \mathrm{~mL})$ was drawn from the gastric cancer patients and the controls, and the blood samples were stored at $-20^{\circ} \mathrm{C}$. Genotyping of ERCCl rs11615 and rs3212986, and ERCC2 rs13181 and rs1799793 gene polymorphisms was carried out by polymerase chain reaction (PCR) coupled with restriction fragment length polymorphism. The primer sequences for ERCC1 rs11615 and rs3212986, and ERCC2 rs13181 and rs1799793 were designed using the Primer premier v5.0 software (Applied Biosystems). The primers and PCR conditions are shown in Table 1. The PCR conditions were as follows: $95^{\circ} \mathrm{C}$ for $5 \mathrm{~min} ; 30$ cycles of $95^{\circ} \mathrm{C}$ for $30 \mathrm{~s}, 60^{\circ} \mathrm{C}$ for $30 \mathrm{~s}$, and $72^{\circ} \mathrm{C}$ for $30 \mathrm{~s}$; and a final extension step of $72^{\circ} \mathrm{C}$ for $10 \mathrm{~min}$.

Table 1. Methodology for polymerase chain reaction (PCR) coupled with restriction fragment length
polymorphism (RFLP) analysis.
\begin{tabular}{l|l|l|c}
\hline Gene & SNP & Primers & Product (bp) \\
\hline$E R C C 1$ & rs11615 & $\begin{array}{l}5 \text {-GCAGAGCTCACCTGAGGAAC-3' } \\
\text { 5'-GAGGTGCAAGAAGAGGTGGA-3' }\end{array}$ & 285 \\
\hline$E R C C 1$ & rs3212986 & $\begin{array}{l}\text { 5'-CAGAGACAGTGCCCCAAGAG-3' } \\
\text { 5'-GGGCACCTTCAGCTTTCTTT-3' }\end{array}$ & 380 \\
\hline$E R C C 2$ & rs13181 & $\begin{array}{l}\text { 5'-GGCAAGACTCAGGAGTCACC-3' } \\
\text { 5'-CCCTCTCCCTTTCCTCTGTT-3' }\end{array}$ & 171 \\
\hline$E R C C 2$ & rs1799793 & 5'-CAGCTCATCTCTCCGCAGGATCAA-3' \\
& 5'-GTCGGGGCTCACCCTGCAGCACTTCCT-3' & 117 \\
\hline
\end{tabular}

$\mathrm{SNP}=$ single-nucleotide polymorphism.

\section{Statistical analysis}

Continuous variables are reported as means \pm standard deviation and categorical variables are expressed as number $(\mathrm{N})$ and percentage (\%). The association between ERCC1 rs11615 and rs3212986, and ERCC2 rs13181 and rs1799793 and the response to chemotherapy was analyzed by logistic regression analysis, and the results are described using odds ratios (ORs) and 95\% confidence intervals (95\%CIs). The association between ERCC1 rs11615 and rs3212986, and ERCC2 rs13181 and rs1799793 with OS of gastric cancer was assessed using 
multivariate analysis using the Cox proportional hazards models, and the results are described by hazard ratios (HRs) and $95 \%$ CIs. A P value less than 0.05 was considered statistically significant. Statistical analysis was carried out using the statistical package SPSS 18 software (version 18.0, SPSS Inc., Chicago, IL, USA).

\section{RESULTS}

The median age of the gastric cancer patients was $57.4 \pm 9.20$ years. There were 79 (35.27\%) females and $145(64.73 \%)$ males in our study. Of the 224 gastric cancer patients, 87 (38.84\%) were of the intestinal type according to Lauren's classification, $137(61.16 \%)$ were of the diffuse type, $33(14.73 \%)$ were at the I-II TNM stage, $191(85.27 \%)$ were at the III-IV TNM stage, 141 (62.95\%) showed positive lymphatic metastasis, and $142(63.39 \%)$ showed $\mathrm{CR}+\mathrm{PR}$ response to chemotherapy (Table 2).

\begin{tabular}{|c|c|c|}
\hline Characteristics & Patients with gastric cancer & $\%$ \\
\hline Age (years) & $57.40 \pm 9.20$ & \\
\hline \multicolumn{3}{|l|}{ Gender } \\
\hline Female & 79 & 35.27 \\
\hline Male & 145 & 64.73 \\
\hline \multicolumn{3}{|c|}{ Lauren's classification } \\
\hline Intestinal & 87 & 38.84 \\
\hline Diffuse & 137 & 61.16 \\
\hline \multicolumn{3}{|l|}{ TNM stage } \\
\hline I-II & 33 & 14.73 \\
\hline III-IV & 191 & 85.27 \\
\hline \multicolumn{3}{|c|}{ Lymphatic metastasis } \\
\hline Negative & 83 & 37.05 \\
\hline Positive & 141 & 62.95 \\
\hline \multicolumn{3}{|c|}{ Response to chemotherapy } \\
\hline $\mathrm{CR}+\mathrm{PR}$ & 142 & 63.39 \\
\hline $\mathrm{SD}+\mathrm{PD}$ & 82 & 36.61 \\
\hline
\end{tabular}

$\mathrm{CR}=$ complete remission, $\mathrm{PR}=$ partial remission, $\mathrm{SD}=$ stable disease, $\mathrm{PD}=$ progressive disease.

The relationships between ERCC1 rs11615 and rs3212986, and ERCC2 rs13181 and rs1799793 gene polymorphisms and the response to chemotherapy in gastric cancer patients are shown in Table 3. By logistic regression analysis, we found that the AA genotype of ERCC1 rs3212986 was associated with lower rates of CR + PR following chemotherapy in gastric cancer patients, and the OR $(95 \% \mathrm{CI})$ was $0.19(0.06-0.60)$. However, we did not find an association between ERCC1 rs11615, ERCC2 rs13181, and ERCC2 rs1799793 and response to chemotherapy.

Up to December 2014, 63 patients died during the follow-up period, and the five-year OS rate was $71.88 \%$. We found that the AA genotype of ERCC1 rs3212986 was correlated with higher risk of death from gastric cancer using the Cox proportional hazards models, and the adjusted HR $(95 \% \mathrm{CI})$ was $1.60(0.81-3.16)$ (Table 4$)$. However, no association between ERCC1 rs11615, ERCC2 rs13181, and ERCC2 rs1799793 and OS in gastric cancer was found using the Cox proportional hazards models. 
Table 3. Association between ERCC1 and ERCC2 gene polymorphisms and response to chemotherapy.

\begin{tabular}{|c|c|c|c|c|c|c|c|c|}
\hline SNPs & Patients & $\%$ & $\mathrm{CR}+\mathrm{PR}$ & $\%$ & SD + PD & $\%$ & OR $(95 \% \mathrm{CI})^{1}$ & P value \\
\hline \multicolumn{9}{|c|}{ rs11615 } \\
\hline TT & 108 & 48.21 & 72 & 50.70 & 36 & 43.90 & 1.0 (Ref.) & - \\
\hline TC & 94 & 41.96 & 58 & 40.85 & 36 & 43.90 & $0.81(0.43-1.49)$ & 0.46 \\
\hline $\mathrm{CC}$ & 22 & 9.82 & 12 & 8.45 & 10 & 12.20 & $0.60(0.21-1.72)$ & 0.28 \\
\hline \multicolumn{9}{|c|}{ rs3212986 } \\
\hline $\mathrm{CC}$ & 113 & 50.45 & 80 & 56.34 & 33 & 40.24 & 1.0 (Ref.) & - \\
\hline $\mathrm{CA}$ & 93 & 41.52 & 56 & 39.44 & 37 & 45.12 & $0.62(0.34-1.16)$ & 0.11 \\
\hline $\mathrm{AA}$ & 19 & 8.48 & 6 & 4.23 & 13 & 15.85 & $0.19(0.06-0.60)$ & $<0.001$ \\
\hline \multicolumn{9}{|c|}{ rs13181 } \\
\hline $\mathrm{AA}$ & 116 & 51.79 & 77 & 54.23 & 39 & 47.56 & 1.0 (Ref.) & - \\
\hline $\mathrm{AC}$ & 84 & 37.50 & 51 & 35.92 & 33 & 40.24 & $0.78(0.42-1.46)$ & 0.41 \\
\hline $\mathrm{CC}$ & 24 & 10.71 & 14 & 9.86 & 10 & 12.20 & $0.71(0.27-1.96)$ & 0.45 \\
\hline \multicolumn{9}{|c|}{ rs1799793 } \\
\hline GG & 124 & 55.36 & 82 & 57.75 & 42 & 51.22 & 1.0 (Ref.) & - \\
\hline GA & 76 & 33.93 & 46 & 32.39 & 30 & 36.59 & $0.79(0.42-1.48)$ & 0.42 \\
\hline $\mathrm{AA}$ & 24 & 10.71 & 14 & 9.86 & 10 & 12.20 & $0.72(0.27-1.97)$ & 0.46 \\
\hline
\end{tabular}

SNP $=$ single-nucleotide polymorphism. ${ }^{1}$ Adjusted for age, gender, Lauren's classification, TNM stage, and lymphatic metastasis.

Table 4. Association between $E R C C 1$ and $E R C C 2$ gene polymorphisms and overall survival of gastric cancer.

\begin{tabular}{|c|c|c|c|c|c|c|c|c|}
\hline Genotypes & Patients & $\%$ & Death & $\%$ & Alive & $\%$ & HR $(95 \% \mathrm{CI})^{1}$ & P value \\
\hline \multicolumn{9}{|l|}{ rs11615 } \\
\hline TT & 108 & 48.21 & 29 & 46 & 79 & 49.07 & 1.0 (Ref.) & - \\
\hline $\mathrm{TC}$ & 94 & 41.96 & 27 & 42.8 & 67 & 41.61 & $1.10(0.56-2.13)$ & 0.77 \\
\hline $\mathrm{CC}$ & 22 & 9.82 & 7 & 11.2 & 15 & 9.32 & $1.27(0.39-3.73)$ & 0.64 \\
\hline rs 3212986 & & & & & & 0.00 & & \\
\hline $\mathrm{CC}$ & 113 & 50.45 & 24 & 43.6 & 89 & 55.28 & 1.0 (Ref.) & - \\
\hline $\mathrm{CA}$ & 93 & 41.52 & 28 & 43.7 & 65 & 40.37 & $1.60(0.81-3.16)$ & 0.14 \\
\hline AA & 19 & 8.48 & 11 & 12.7 & 8 & 4.97 & $5.10(1.63-16.17)$ & $<0.001$ \\
\hline rs13181 & & & & & & 0.00 & & \\
\hline AA & 116 & 51.79 & 31 & 48.5 & 85 & 52.80 & 1.0 (Ref.) & - \\
\hline $\mathrm{AC}$ & 84 & 37.5 & 24 & 38.7 & 60 & 37.27 & $1.10(0.56-2.15)$ & 0.77 \\
\hline $\mathrm{CC}$ & 24 & 10.71 & 8 & 12.8 & 16 & 9.94 & $1.37(0.46-3.80)$ & 0.51 \\
\hline rs1799793 & & & & & & 0.00 & & \\
\hline GG & 124 & 55.36 & 33 & 52.1 & 91 & 56.52 & 1.0 (Ref.) & - \\
\hline GA & 76 & 33.93 & 22 & 35.5 & 54 & 33.54 & $1.12(0.56-2.22)$ & 0.72 \\
\hline AA & 24 & 10.71 & 8 & 12.4 & 16 & 9.94 & $1.38(0.46-3.80)$ & 0.5 \\
\hline
\end{tabular}

${ }^{1}$ Adjusted for age, gender, Lauren's classification, TNM stage, and lymphatic metastasis.

\section{DISCUSSION}

The ERCC1 enzyme belongs to the NER system, and has the ability to repair DNA adducts and other DNA helix-distorting lesions (de Laat et al., 1999), including platinum intrastrand DNA adducts; it is thought to be involved in resistance to platinum-based chemotherapy via reducing platinum-induced DNA damage (Kwon et al., 2007; Kawashima et al., 2011). In our study, we found that the AA genotype of ERCC1 rs3212986 was associated with the response to platinum-based chemotherapy and OS in gastric cancer patients.

The ERCC1 enzyme is involved in recognizing and removing platinum-induced intrastrand adducts in DNA; previous studies have reported that ERCCl gene polymorphisms are associated with the response to platinum-based chemotherapy in patients with osteosarcoma, breast cancer, non-small cell lung cancer, and colorectal cancer (Bewick et al., 2011; Qian et 
al., 2014; Ji and He, 2015; Shi et al., 2015). Guo et al. (2015) conducted a study in a Canadian population, and found that the ERCC1 rs3212986 polymorphism was not associated with the survival outcome of patients with breast cancer. Ji and He (2015) conducted a study in a Chinese population, and found that the ERCCl rs11615 polymorphism plays an important role in the response to chemotherapy and OS in osteosarcoma. Shi et al. (2015) also conducted a study in a Chinese population, and found that the ERCC1 rs11615 polymorphism influences the chemotherapy and survival of patients with non-small cell lung cancer. Qian et al. (2014) reported that the ERCC1 rs11615 polymorphism is associated with prognosis in colorectal cancer patients. The studies mentioned above suggest that ERCC1 gene polymorphisms are associated with prognosis in cancer.

Several previous studies have reported an association between ERCCl gene polymorphisms and prognosis in gastric cancer (Li et al., 2014; Liu et al., 2014; Ma et al., 2015; Xue et al., 2015; Yu et al., 2015; Zhou et al., 2015). Xue et al. (2015) reported that ERCC1 rs 11615 and rs3212986 polymorphisms affect the clinical outcome of patients with gastric cancer. Another study in a Chinese population reported that ERCC1 rs11615 and rs2298881 contribute to the response to chemotherapy and clinical outcome in gastric cancer patients (Yu et al., 2015). Zhou et al. (2015) reported that the ERCC1 rs11615 polymorphism influences the treatment outcome in gastric cancer. Ma et al. (2015) conducted a meta-analysis comprising 22 studies, and reported that the ERCC1 rs 11615 polymorphism was correlated with prognosis in gastric cancer patients treated with platinum-based chemotherapy. In this study, we hypothesized that the AA genotype of ERCC1 rs3212986 influences the response to platinum-based chemotherapy and OS in gastric cancer patients, which was inconsistent with our results. The inconsistency might have been due to differences in ethnicity, patient sources, sample size, and by chance.

In conclusion, the results of the present retrospective study indicate that the ERCC1 rs3212986 gene polymorphism has a significant effect on the pharmacokinetics and treatment outcome of gastric cancer. Future studies with larger sample sizes are needed to confirm the role of ERCC1 and ERCC2 gene polymorphisms in the treatment outcome for gastric cancer patients.

\section{Conflicts of interest}

The authors declare no conflict of interest.

\section{ACKNOWLEDGMENTS}

We thank for the help from staffs in the Ruikang Hospital Affiliated to Guangxi University of Chinese Medicine for collecting the gastric cancer patients.

\section{REFERENCES}

Bewick MA, Lafrenie RM and Conlon MS (2011). Nucleotide excision repair polymorphisms and survival outcome for patients with metastatic breast cancer. J. Cancer Res. Clin. Oncol. 137: 543-550. http://dx.doi.org/10.1007/s00432010-0915-7

Coin F, Oksenych V and Egly JM (2007). Distinct roles for the XPB/p52 and XPD/p44 subcomplexes of TFIIH in damaged DNA opening during nucleotide excision repair. Mol. Cell 26: 245-256. http://dx.doi.org/10.1016/j. molcel.2007.03.009

de Laat WL, Jaspers NG and Hoeijmakers JH (1999). Molecular mechanism of nucleotide excision repair. Genes Dev. 13: 768-785. http://dx.doi.org/10.1101/gad.13.7.768 
Enzlin JH and Schärer OD (2002). The active site of the DNA repair endonuclease XPF-ERCC1 forms a highly conserved nuclease motif. EMBO J. 21: 2045-2053. http://dx.doi.org/10.1093/emboj/21.8.2045

Evans E, Moggs JG, Hwang JR, Egly JM, et al. (1997). Mechanism of open complex and dual incision formation by human nucleotide excision repair factors. EMBO J. 16: 6559-6573. http://dx.doi.org/10.1093/emboj/16.21.6559

Goode EL, Ulrich CM and Potter JD (2002). Polymorphisms in DNA repair genes and associations with cancer risk. Cancer Epidemiol. Biomarkers Prev. 11: 1513-1530.

Guo XG, Wang Q, Xia Y and Zheng L (2015). The C8092A polymorphism in the ERCC1 gene and breast carcinoma risk: a meta-analysis of case-control studies. Int. J. Clin. Exp. Med. 8: 3691-3699.

Ji WP and He NB (2015). Investigation on the DNA repaired gene polymorphisms and response to chemotherapy and overall survival of osteosarcoma. Int. J. Clin. Exp. Pathol. 8: 894-899.

Kawashima A, Nakayama M, Kakuta Y, Abe T, et al. (2011). Excision repair cross-complementing group 1 may predict the efficacy of chemoradiation therapy for muscle-invasive bladder cancer. Clin. Cancer Res. 17: 2561-2569. http:// dx.doi.org/10.1158/1078-0432.CCR-10-1963

Kwon HC, Roh MS, Oh SY, Kim SH, et al. (2007). Prognostic value of expression of ERCC1, thymidylate synthase, and glutathione S-transferase P1 for 5-fluorouracil/oxaliplatin chemotherapy in advanced gastric cancer. Ann. Oncol. 18: 504-509. http://dx.doi.org/10.1093/annonc/mdl430

Li J, Zuo X, Lv X, Kong F, et al. (2014). Association of DNA repair gene polymorphisms with response to chemotherapy and prognosis of gastric cancer in a Chinese population. Tumour Biol. 35: 7569-7574. http://dx.doi.org/10.1007/ $\underline{\text { s13277-014-1959-0 }}$

Lindahl T and Wood RD (1999). Quality control by DNA repair. Science 286: 1897-1905. http://dx.doi.org/10.1126/ science.286.5446.1897

Liu L, Li CH, Jin TF and Xu DY (2014). Study on the ERCC1 gene polymorphism response to chemotherapy and prognosis of gastric cancer. Genet. Mol. Res. 13: 8722-8728. http://dx.doi.org/10.4238/2014.October.27.13

Ludwig JA and Weinstein JN (2005). Biomarkers in cancer staging, prognosis and treatment selection. Nat. Rev. Cancer 5: 845-856. http://dx.doi.org/10.1038/nrc1739

Ma SC, Zhao Y, Zhang T, Ling XL, et al. (2015). Association between the ERCC1 rs11615 polymorphism and clinical outcomes of oxaliplatin-based chemotherapies in gastrointestinal cancer: a meta-analysis. Onco Targets Ther. 8: 641-648.

Matsunaga T, Mu D, Park CH, Reardon JT, et al. (1995). Human DNA repair excision nuclease. Analysis of the roles of the subunits involved in dual incisions by using anti-XPG and anti-ERCC1 antibodies. J. Biol. Chem. 270: 2086220869. http://dx.doi.org/10.1074/jbc.270.35.20862

Miller AB, Hoogstraten B, Staquet M and Winkler A (1981). Reporting results of cancer treatment. Cancer 47: 207-214. http://dx.doi.org/10.1002/1097-0142(19810101)47:1<207::AID-CNCR2820470134>3.0.CO;2-6

Ohtsu A (2008). Chemotherapy for metastatic gastric cancer: past, present, and future. J. Gastroenterol. 43: 256-264. http://dx.doi.org/10.1007/s00535-008-2177-6

Parkin DM, Bray F, Ferlay J and Pisani P (2005). Global cancer statistics, 2002. CA Cancer J. Clin. 55: 74-108. http:// dx.doi.org/10.3322/canjclin.55.2.74

Qian YY, Liu XY, Wu Q, Song X, et al. (2014). The ERCC1 C118T polymorphism predicts clinical outcomes of colorectal cancer patients receiving oxaliplatin-based chemotherapy: a meta-analysis based on 22 studies. Asian Pac. J. Cancer Prev. 15: 8383-8390. http://dx.doi.org/10.7314/APJCP.2014.15.19.8383

Shi ZH, Shi GY and Liu LG (2015). Polymorphisms in ERCC1 and XPF gene and response to chemotherapy and overall survival of non-small cell lung cancer. Int. J. Clin. Exp. Pathol. 8: 3132-3137.

Xue MH, Li GY, Wu XJ, Zhang CX, et al. (2015). Genetic variability of genes in NER pathway influences the treatment outcome of gastric cancer. Int. J. Clin. Exp. Pathol. 8: 5563-5569.

Yang X, Takano Y and Zheng HC (2012). The pathobiological features of gastrointestinal cancers (Review). Oncol. Lett. 3: $961-969$.

Yu H, Wu X, Zhang Y, Jin Z, et al. (2015). Genetic variability of DNA repair mechanisms influences chemotherapy outcome of gastric cancer. Int. J. Clin. Exp. Pathol. 8: 4106-4112.

Zhou J, Liu ZY, Li CB, Gao S, et al. (2015). Genetic polymorphisms of DNA repair pathways influence the response to chemotherapy and overall survival of gastric cancer. Tumour Biol. 36: 3017-3023. http://dx.doi.org/10.1007/s13277014-2936-3 